Research Article

\title{
QCM Analysis for Two-Step Adsorption of Albumin and Fibronectin on Zirconia Surface
}

\author{
Masatsugu Hirota $\mathbb{D}^{1}$ and Tohru Hayakawa ${ }^{2}$ \\ ${ }^{1}$ Department of Education for Dental Medicine, Tsurumi University School of Dental Medicine, Yokohama, Kanagawa, Japan \\ ${ }^{2}$ Department of Dental Engineering, Tsurumi University School of Dental Medicine, Yokohama, Kanagawa, Japan \\ Correspondence should be addressed to Masatsugu Hirota; hirota-masatsugu@tsurumi-u.ac.jp
}

Received 12 April 2021; Revised 26 July 2021; Accepted 4 August 2021; Published 18 August 2021

Academic Editor: MariaGabriella Santonicola

Copyright ( 2021 Masatsugu Hirota and Tohru Hayakawa. This is an open access article distributed under the Creative Commons Attribution License, which permits unrestricted use, distribution, and reproduction in any medium, provided the original work is properly cited.

\begin{abstract}
The adsorption of proteins on the dental implant surface is the first step in the key role of osseointegration. Many types of proteins exist in the living body and compete for adsorption on the material surface. As an implant material, partially stabilized zirconia $\left(\mathrm{ZrO}_{2}\right)$ is currently an attractive alternative to titanium to overcome the shortcomings of titanium implants. In this study, we investigated the two-step adsorption of fibronectin ( $\mathrm{Fn}$ ) and bovine serum albumin (Alb) on the $\mathrm{ZrO}_{2}$ surface using a 27-MHz quartz crystal microbalance (QCM) method. A $\mathrm{ZrO}_{2}$ sensor was employed for the QCM measurements. Two-step adsorptions were performed as follows. (1) Fn-Alb series: first, the Fn solution was injected into the phosphate-buffered saline (PBS) solution, followed by the Alb solution. (2) Alb-Fn series: first, the Alb solution was injected, followed by the Fn solution. The decrease in frequency was monitored for 60 minutes after each protein injection. The adsorbed amounts of Fn or Alb were calculated by observing the decrease in frequency, and the apparent reaction rate, $k_{\mathrm{obs}}$, was obtained through the curve fitting of frequency shift against the adsorption time. No significant difference was observed in the adsorbed amounts of Fn and Alb between the Fn-Alb and Alb-Fn series $(P>0.05)$. The $k_{\mathrm{obs}}$, rate of protein adsorption, in the second step was significantly slower than that in the first step for both Fn and Alb adsorption $(P<0.05)$. There was no clear correlation between the amount of protein adsorbed on the $\mathrm{ZrO}_{2}$ sensor and the surface topography. It was concluded that the amount of protein adsorbed on the $\mathrm{ZrO}_{2}$ surface was not influenced by the two-step adsorption series, but the adsorption rate of proteins in the second step was affected by the first-step protein adsorption.
\end{abstract}

\section{Introduction}

Early new bone formation and subsequent osseointegration formation is one of the most important factors in the success of dental implant treatment [1]. Trindade et al. reported that osseointegration is a multistage process, in which the first step is the attachment or adsorption of proteins on the surface of dental implant materials [2]. Kasemo et al. reported that adsorbed proteins affect cell adhesion. Inflammation begins with bleeding during the wound healing process. Subsequently, mesenchymal stem cells and osteoblasts induce the differentiation and promotion of bone formation $[3,4]$. It is suggested that the presence of adhesive proteins and/or bone formationrelated proteins on the material surface controls new bone formation. The study of the adsorption behaviors of these proteins on the implant surface is therefore important to understand the mechanism of osseointegration.

In the last decade, dental zirconia $\left(\mathrm{ZrO}_{2}\right)$ implants have been introduced in dental clinics. The zirconia used for dental implants is tetragonal zirconia stabilized by the addition of approximately 3-4\% yttria (Y-TZP) [5, 6]. Y-TZP, a white ceramic material, has superior mechanical properties, such as bending strength and high fracture toughness, owing to the stress-induced transformation mechanism. Therefore, it can overcome the shortcomings of titanium, such as dark grayish color and/ or metal sensitivity [7-9]. Various surface modifications in zirconia implants have been reported to achieve tight 
and fast bone bonding and the formation of osseointegration [10-13].

Quartz crystal microbalance (QCM) is a sensing device used to monitor protein adsorption behavior on the material surface [14]. The QCM technique is a straightforward method used to detect the adsorption or desorption of proteins on a material surface by measuring the differences in the oscillating frequency of the quartz sensor cell. The adsorption of protein on the surface of an oscillating quartz crystal causes a decrease in the oscillation frequency in relation to the amount of protein bound to the crystal surface. The amount of protein adsorbed on the biomaterial can be estimated using the Sauerbrey equation [15].

Numerous studies on protein adsorption using the QCM method have been reported [16-18]. We investigated the protein adsorption on implant materials using the QCM method. For example, Kusakawa et al. evaluated the protein adsorption on $\mathrm{ZrO}_{2}$ or Ti using QCM. They found that the protein adsorption amounts of fibronectin and albumin on Ti were larger than those on $\mathrm{ZrO}_{2}$ [19]. Yoshida and Hayakawa used the QCM method to investigate lactoferrin adsorption on $\mathrm{Ti}$, stainless steel, $\mathrm{ZrO}_{2}$, and polymethyl methacrylate surfaces. Ti and stainless steel showed a greater amount of lactoferrin adsorption than $\mathrm{ZrO}_{2}$ and polymethyl methacrylate [20].

Many types of proteins exist in the living body, which compete for adsorption on the material surface. It is presumed that the preadsorption of proteins influences the continuous adsorption of other proteins. Pegueroles et al. investigated the competition of protein adsorption on the $\mathrm{TiO}_{2}$ surface in two-step adsorption experiments using the QCM method [21]. They used fibrinogen (Fbg), fibronectin (Fn), and albumin (Alb) as proteins and found that two-step adsorption on the $\mathrm{TiO}_{2}$ surface was influenced by the differences between the proteins. Imagami et al. reported that preadsorbed proteins influence the adsorption of proteins during the second step by monitoring the two-step adsorption of Fn and Alb on Ti in the QCM analysis method [22]. There are no reports of two-step adsorption on $\mathrm{ZrO}_{2}$ surface using the QCM method.

In this study, we aimed to investigate the adsorption of different proteins on the $\mathrm{ZrO}_{2}$ surface in a two-step adsorption system using the QCM method. Fn, a cell-adhesive protein, and Alb, a cell adhesion inhibiting protein, were evaluated as proteins, and sequential adsorption was conducted in the QCM sensor cell.

\section{Methods}

2.1. QCM Device and Sensor. Figure 1 shows the QCM device and the mounted sensor used in this study. A 27-MHz QCM (AFFINIX QN $\mu$, ULVAC, Inc., Kanagawa, Japan) with $550 \mu \mathrm{L}$ sensor cells was used. The temperature was maintained at $25 \pm 1^{\circ} \mathrm{C}$ using a temperature control system, and the solution in the cells was stirred during the measurements. The AT-cut quartz crystal was sandwiched between gold electrodes on both sides. The surface area of the $\mathrm{Au}$ electrode was $4.9 \mathrm{~mm}^{2}$.
$\mathrm{ZrO}_{2}$ sensors were used in the study. This sensor was prepared by sputter coating on the $\mathrm{Au}$ electrode using sputtering deposition equipment (CS200, ULVAC, Inc. Kanagawa, Japan). The zirconium target was sputtered at $0.5 \mathrm{~Pa}$ in an oxygen chamber for 30 minutes. The film thickness of sputtered zirconia has been reported to have a thickness of $115 \mathrm{~nm}$ using a profilometer in our previous study [23]. The $\mathrm{ZrO}_{2}$ sensor was assembled in a sensor cell and irradiated with ultraviolet radiation (BioForce Nanosciences Holdings Inc., VA, US) for 20 minutes before QCM measurement. UV irradiation of $15 \mathrm{~mW} / \mathrm{cm}^{2}$ was emitted perpendicularly to the sensors at a distance of $20 \mathrm{~mm}$ at $\lambda=254 \mathrm{~nm}$. After irradiation, the $\mathrm{ZrO}_{2}$ sensor cell was mounted on the cell socket of the QCM apparatus, as shown in Figure 1. UV irradiation on $\mathrm{ZrO}_{2}$ surface removes the contamination and makes the surface fresh [24].

2.2. EPMA Mapping Analysis of $\mathrm{ZrO}_{2}$ Sensors. The $\mathrm{ZrO}_{2}$ sensor surfaces after ultraviolet irradiation were evaluated by electron probe microanalysis (EPMA, JXA-8900R, JEOL Ltd., Tokyo, Japan) at an accelerating voltage of $20 \mathrm{kV}$ by detecting the X-ray intensities of $\mathrm{Zr}-\mathrm{K} \alpha$. The presence of $\mathrm{Zr}$ was confirmed by elementary mapping.

2.3. AFM Observation of Sensor. An atomic force microscope (AFM; Nanosurf Easyscan 2, Nanosurf, AG, Switzerland) was used to identify the surface conditions and surface roughness of the $\mathrm{ZrO}_{2}$ sensor before and after protein adsorption. Fn or $\mathrm{Alb}$ was adsorbed on the $\mathrm{ZrO}_{2}$ sensor, as described above. After rinsing the excess amount of adsorbed Fn or Alb with double-distilled water for 20 seconds, each surface was observed. The AFM images were obtained for an area of $5 \times 5 \mu \mathrm{m}^{2}$. The three-dimensional arithmetic height $(\mathrm{Sa})$ was calculated as a surface roughness parameter. All measurements were performed five times for each sample. Tapping mode silicon probes (Tap190Al-G, force contact $48 \mathrm{~N} / \mathrm{m}$, Budget sensors, Sofia, Bulgaria) with resonance frequencies of approximately $190 \mathrm{kHz}$ were used to perform AFM imaging.

2.4. Contact Angle Measurement of $\mathrm{ZrO}_{2}$ Sensors. The contact angles of the $\mathrm{ZrO}_{2}$ sensor before and after protein adsorption with respect to double-distilled water were measured using a contact angle meter (DMe-201, Kyowa Interface Science Co. Ltd., Tokyo, Japan). $\mathrm{ZrO}_{2}$ sensor was measured after ultraviolet irradiation of each sensor. Fn or Alb was adsorbed on the $\mathrm{ZrO}_{2}$ sensor, as described above. After rinsing the excess amount of adsorbed Fn or Alb with double-distilled water for 20 seconds, each surface was observed. The water drop volume was maintained at $0.5 \mu \mathrm{L}$, and the contact angle was the measured value 3 seconds after dripping. Measurements were performed five times at the same room temperature and humidity.

2.5. QCM Measurement through Two-Step Adsorption of Proteins. Human plasma fibronectin (Fn, Harbor BioProducts, MA, USA) and bovine serum albumin (Alb, Wako 


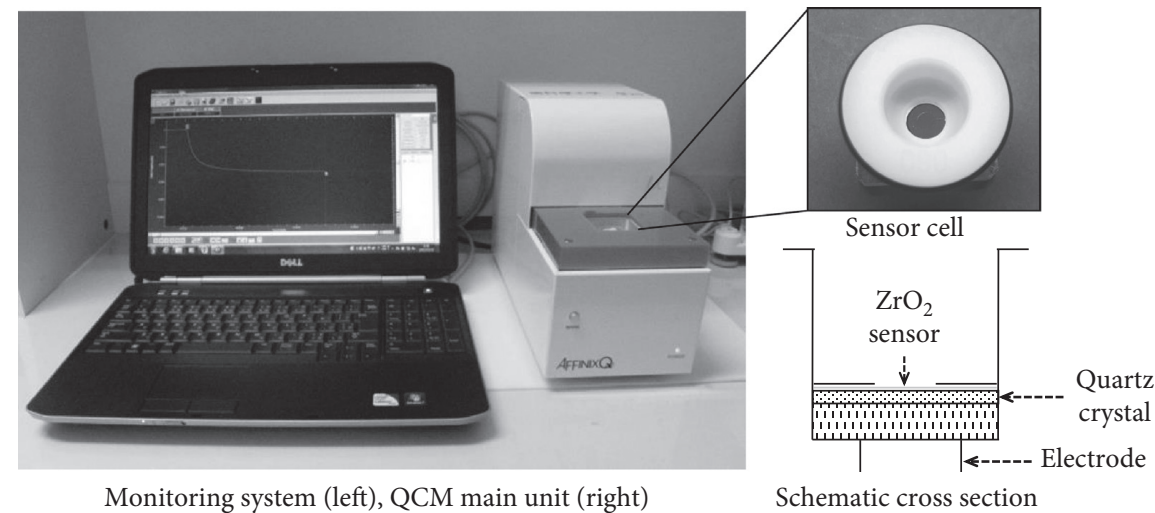

Figure 1: QCM devise and mounted sensor used in this study.

Pure Chemical Inds. Ltd., Osaka, Japan) were dissolved in a phosphate-buffered saline (PBS) solution ( $\mathrm{pH} 7.4$ ) with a concentration of $0.5 \mathrm{mg} / \mathrm{mL}$. Fn used in the present study is a dimer of $220 \mathrm{kDa}$ glycoprotein. Dimers are connected by a pair of C-terminal S-S bonds. Fn is well-known cell-adhesive protein. Integrin which is a transmembrane receptor binds to RGD (Arg-Gly-Asp) motif of Fn. Molecular weight of Alb in the present study is approximately $6-7 \mathrm{kDa}$. Alb is a small protein compared to other proteins and exhibits cyclic threedimensional structure. Serum Alb is major component in serum. Alb is known as cell-adhesion inhibiting protein as mentioned.

A typical frequency-decrease curve is shown in Figure 2. A two-stage decrease in frequency was observed based on the two-step adsorption of proteins. The sensor cell with the $\mathrm{ZrO}_{2}$ sensor was filled with $500 \mu \mathrm{L}$ of PBS. After stabilization of the frequency shift, two-step adsorption of Fn and Alb was monitored in the following two series.

(1) Fn-Alb series: in the first step, $5 \mu \mathrm{L}$ of Fn solution was injected into the PBS solution in the cell. The decrease in frequency due to Fn adsorption on the $\mathrm{ZrO}_{2}$ sensor was monitored for 60 minutes after Fn injection. In the second step, $5 \mu \mathrm{L}$ of Alb solution was injected on the Fn preadsorbed sensor into the PBS solution in the cell, and the decrease in frequency was monitored for an additional 60 minutes.

(2) Alb-Fn series: first, $5 \mu \mathrm{L}$ of Alb solution was injected. After 60 minutes of Alb injection, $5 \mu \mathrm{L}$ of Fn solution was injected on the Alb preadsorbed sensor in the second step. The decrease in frequency was monitored for an additional 60 minutes.

The amount of Fn and Alb adsorbed on the $\mathrm{ZrO}_{2}$ sensor surface $(\Delta m)$ was calculated 60 minutes after each protein injection using Sauerbrey's equation [15]:

$$
\Delta F=\frac{-2 F_{0}^{2} \Delta m}{A \sqrt{\rho_{q} \mu_{q}}},
$$

where $\Delta F$ is the measured frequency shift $(\mathrm{Hz}), \Delta m$ is the mass change $(\mathrm{g}), F_{0}$ is the fundamental frequency of the quartz crystal $\left(27 \times 10^{6} \mathrm{~Hz}\right), A$ is the electrode area $\left(0.049 \mathrm{~cm}^{2}\right), \rho_{q}$ is the density of quartz $\left(2.65 \mathrm{~g} / \mathrm{cm}^{3}\right)$, and $\mu_{q}$ is the shear modulus of quartz $\left(2.95 \times 10^{11} \mathrm{dyn} / \mathrm{cm}^{2}\right)$. At $27 \mathrm{MHz}$, a decrease of $1 \mathrm{~Hz}$ in frequency corresponded to a mass change of approximately $0.62 \mathrm{ng} / \mathrm{cm}^{2}$.

Through the curve fitting of $\Delta F$ curve against the adsorption time, the apparent reaction rate, $k_{\text {obs }}$, was obtained using the following equation:

$$
\Delta F_{t}=\Delta F_{\infty}\left(1-e^{-k_{\mathrm{obs}} \cdot t}\right)
$$

Five runs of QCM measurements for two series were performed.

2.6. Statistical Analysis. Significant differences were determined using SPSS version 25 (IBM Japan, Ltd., Tokyo, Japan). The surface roughness data were evaluated by conducting one-way analysis of variance (ANOVA) and the Bonferroni test for multiple comparisons between the means. The data of adsorbed amounts at each step and $k_{\text {obs }}$ at the same time after the injection, i.e., at 5 minutes in the FnAlb series or in the Alb-Fn series, were analyzed using a nonpaired $t$-test. The statistical significance was set at $P<0.05$, and data were expressed as mean \pm standard deviation $(\mathrm{SD})$.

\section{Results}

3.1. EPMA Analysis of $\mathrm{ZrO}_{2}$ Sensor. Figure 3 show the elementary distribution of $\mathrm{Zr}$ on the $\mathrm{ZrO}_{2}$ sensor. Homogeneous sputter coating of $\mathrm{Zr}$ on each sensor surface was confirmed.

3.2. AFM Analysis and Surface Roughness and Contact Angles of $\mathrm{ZrO}_{2}$ Sensor. The AFM images of the native $\mathrm{ZrO}_{2}$ sensor and the Fn- and Alb-adsorbed $\mathrm{ZrO}_{2}$ sensor surfaces after rinsing with double-distilled water are shown in Figure 4. Small particles $(0.2 \mu \mathrm{m}$ or less $)$ formed through the sputtering process were uniformly recognized on the native $\mathrm{ZrO}_{2}$ sensor. After rinsing, some amounts of Alb and Fn were observed on the Fn- and Alb-adsorbed $\mathrm{ZrO}_{2}$ sensors. It appeared that more adsorbed proteins were observed on the Fn-adsorbed sensor than on the Alb-adsorbed sensor. 


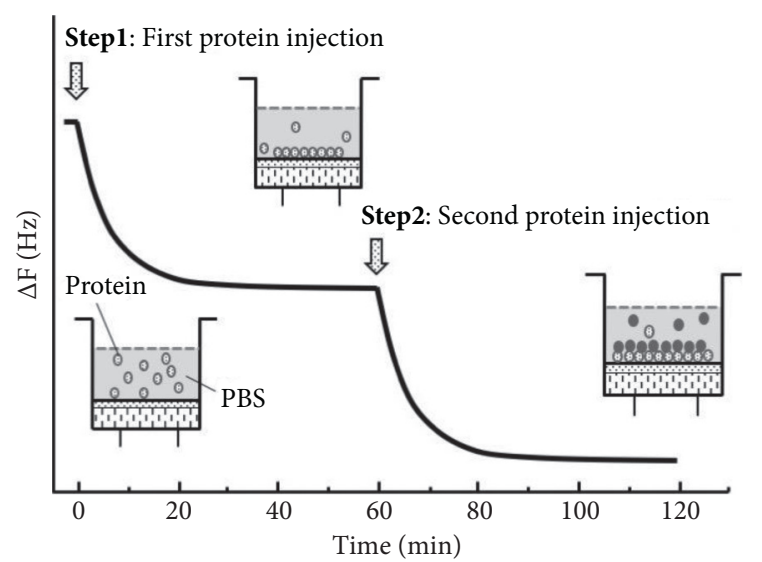

FIGURE 2: Typical frequency-decrease curve and schematic diagram of the sensor cell for QCM measurement using two-step adsorption methods.

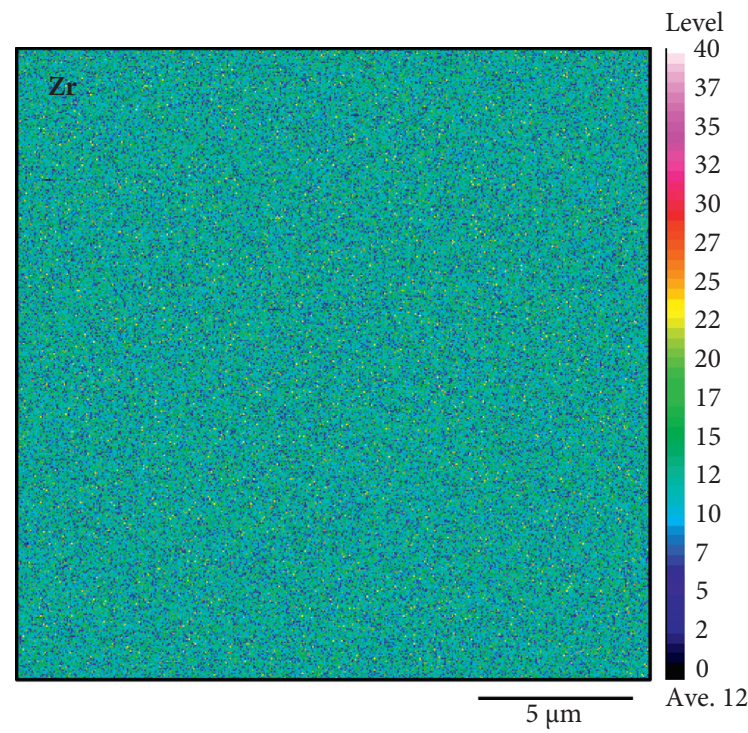

Figure 3: EPMA analysis of surface of zirconia sensor. Zr: zirconium.

The surface roughness $(\mathrm{Sa})$ values and contact angles of the native $\mathrm{ZrO}_{2}$ sensor and the $\mathrm{Fn}$ - and Alb-adsorbed $\mathrm{ZrO}_{2}$ sensor surfaces are listed in Table 1. Fn-adsorbed $\mathrm{ZrO}_{2}$ showed a significantly greater surface roughness than native $\mathrm{ZrO}_{2} \quad(P<0.05)$. No significant difference in surface roughness was observed between Fn-adsorbed and Albadsorbed $\mathrm{ZrO}_{2}(P>0.05)$. Fn- and Alb-adsorbed $\mathrm{ZrO}_{2}$ sensor showed significantly greater contact angles than $\mathrm{ZrO}_{2}$ $(P<0.05)$, and $\mathrm{Fn}$-adsorbed $\mathrm{ZrO}_{2}$ showed a significantly greater contact angle than Alb-adsorbed $\mathrm{ZrO}_{2}(P<0.05)$.

3.3. QCM Measurements through Two-Step Adsorption of Fn and Alb. Figure 5 shows the $\Delta F$ curves for the Fn-Alb and Alb-Fn series to the $\mathrm{ZrO}_{2}$ sensor using QCM measurements. The decrease in $\Delta F$ immediately after the Fn or Alb injection can be monitored, which corresponds to an increase in the adsorption of Fn and Alb. The Fn injection produced a greater decrease in frequency than the Alb injection in both the first and second steps. Eventually, there were no distinct differences in the decrease in frequency between the Fn-Alb and Alb-Fn series, 120 minutes after protein injection.

Figure 6 shows the adsorbed amounts of Fn and Alb on the $\mathrm{ZrO}_{2}$ sensor in different two-step adsorption methods, which were estimated using the Sauerbrey equation [15]. The adsorbed amount of Fn is significantly higher than that of Alb in both the Fn-Alb and Alb-Fn series $(P<0.05)$. No significant differences were observed for Fn and Alb adsorption between the first and second adsorption steps $(P>0.05)$. Moreover, there were no significant differences in total adsorbed protein amounts between the Fn-Alb and Alb-Fn series $(P>0.05)$.

Table 2 lists the $k_{\text {obs }}$ values for the adsorption of Fn and Alb on $\mathrm{ZrO}_{2}$ sensor obtained 5 minutes after injection. A larger value of $k_{\mathrm{obs}}$ indicates a relatively rapid adsorption rate. In both series, Fn shows significantly greater $k_{\text {obs }}$ than Alb $(P<0.05)$, and the $k_{\text {obs }}$ of protein adsorption in the first step is significantly greater than $k_{\text {obs }}$ of protein adsorption in the second step $(P<0.05)$.

\section{Discussion}

In this study, we evaluated the two-step adsorption behavior of fibronectin and albumin on a $\mathrm{ZrO}_{2}$ sensor using a 27$\mathrm{MHz}$ QCM. Two types of proteins, Fn and Alb, were used as a mixed model to simulate body fluid. This study revealed that the preadsorption of proteins in the first step influenced protein adsorption in the second step.

The $\mathrm{ZrO}_{2}$ sensor used in this study was prepared using sputter coating. In the sputtering process, atoms or molecules are ejected from the target material through plasma or gas bombardment. The ejected atoms or molecules are then deposited on the substrate. In this study, zirconium was used as the target for the $\mathrm{ZrO}_{2}$ sensor. Kusakawa et al. prepared a $\mathrm{ZrO}_{2}$ sensor under the same conditions [19]. We confirmed the homogeneous sputter coating of $\mathrm{Zr}$ on a sensor surface in this study. First, we analyzed the surface topographies of the $\mathrm{ZrO}_{2}$ sensor to check its surface conditions. In addition, the surface conditions after the first step of protein adsorption were analyzed.

The adsorption amount of Fn was higher than that of Alb during the first adsorption. This result was the same as the previous result. Our previous studies also reported that the adsorption of Fn was greater than that of Alb on Ti or $\mathrm{ZrO}_{2}$ $[19,25]$. Interestingly, the Fn adsorption amount was significantly larger in the first step as well as in the second step.

Our previous studies on two-step adsorption to Ti showed that the order of protein adsorption influenced the total adsorption amount [22]. The adsorption amounts in the Alb-Fn series were significantly greater than those in the Fn-Alb series. In particular, Fn adsorbed to Alb-adsorbed Ti was more than that absorbed to native Ti. However, the present two-step adsorption study on $\mathrm{ZrO}_{2}$ showed that there were no differences in the total adsorption amounts between the two adsorption series. The adsorption of Fn on 

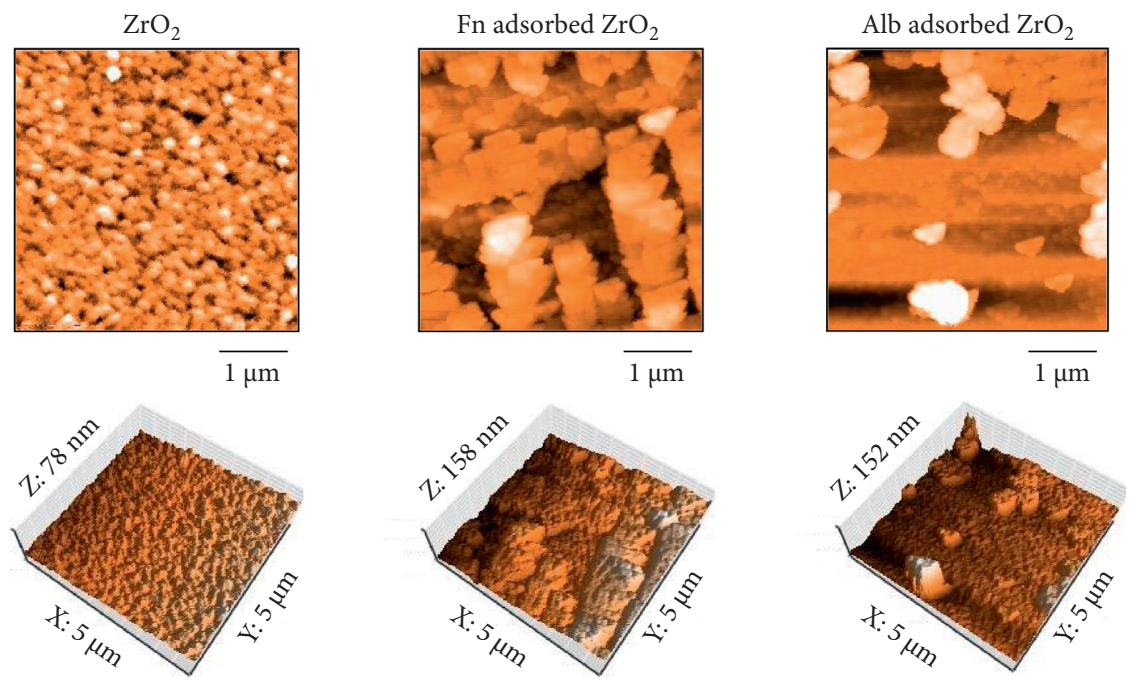

Figure 4: AFM images of a native $\mathrm{ZrO}_{2}$ sensor and Fn- and Alb-adsorbed $\mathrm{ZrO}_{2}$ sensor.

TABle 1: Surface roughness (Sa) and contact angle of a native $\mathrm{ZrO}_{2}$ sensor and Fn- and Alb-adsorbed $\mathrm{ZrO}_{2}$ sensor surfaces $(n=5)$.

\begin{tabular}{lcc}
\hline Sensor & Surface roughness $\left(\mathrm{Sa}\left(\mathrm{nm} / 25 \mu \mathrm{m}^{2}\right)\right)$ & Contact angle $\left(^{\circ}\right)$ \\
\hline $\mathrm{ZrO}_{2}$ & $2.10(0.24)^{\mathrm{a}}$ & $6.04(0.82)^{\mathrm{c}}$ \\
$\mathrm{Fn}$ adsorbed $\mathrm{ZrO}_{2}$ & $8.05(1.91)^{\mathrm{b}}$ & $52.82(2.66)^{\mathrm{d}}$ \\
$\mathrm{Alb}$ adsorbed $\mathrm{ZrO}_{2}$ & $6.63(4.50)^{\mathrm{a}, \mathrm{b}}$ & $24.38(2.31)^{\mathrm{e}}$ \\
\hline
\end{tabular}

Values in brackets are SD. Different superscript letters indicate a significant difference $(P<0.05)$.

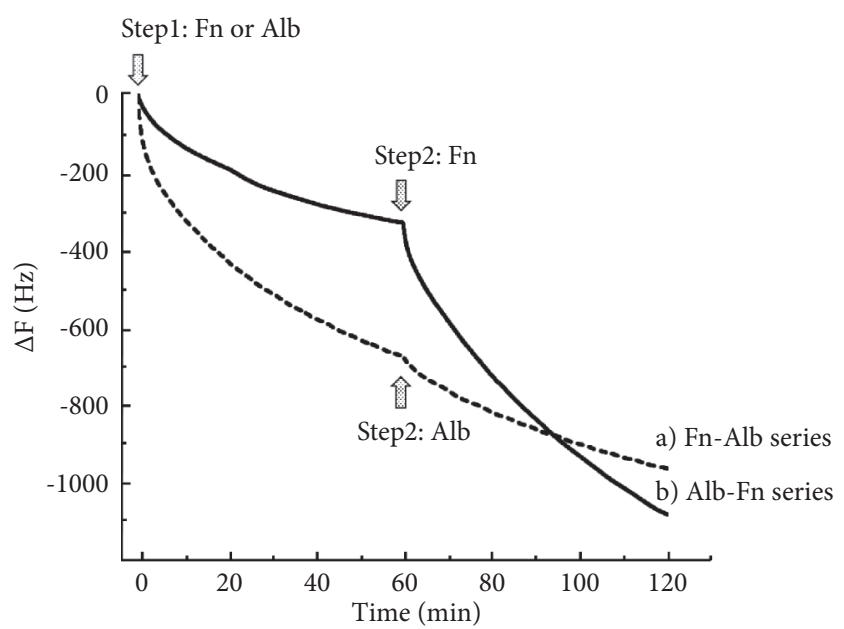

Figure 5: $\Delta F$ curves for Fn-Alb series and Alb-Fn series to $\mathrm{ZrO}_{2}$ sensor using QCM measurements.

Alb-adsorbed $\mathrm{ZrO}_{2}$ and that of $\mathrm{Alb}$ on Fn-adsorbed $\mathrm{ZrO}_{2}$ was almost the same as that on the native $\mathrm{ZrO}_{2}$ surface.

It is well known that the surface roughness of a material influences protein adsorption. More proteins are adsorbed on a rougher surface [26]. However, there was no clear relationship between surface roughness and adsorbed amounts of proteins in the present study. The rough surfaces at the second step of adsorption did not increase the amount of protein adsorption compared to the first step of adsorption.

Hydrophilicity is another important factor in protein adsorption. Wei et al. investigated protein adsorption on a surface with a wide range of wettability [27]. They prepared this surface through the combination of hexamethyldisiloxane film coating and $\mathrm{O}_{2}$-plasma treatment, where the contact angle of water ranged from $0^{\circ}$ to $106^{\circ}$. They reported that Fn was adsorbed on both hydrophilic and hydrophobic surfaces. On the contrary, Alb showed greater adsorption on the hydrophobic surface. UV irradiation produced a hydrophilic $\mathrm{ZrO}_{2}$ surface as a previous report [19]. Proteinadsorbed surfaces in this study are more hydrophobic than $\mathrm{UV}$-irradiated native surfaces. It was predicted that more amount of Fn adsorbed surface to UV-irradiated native surfaces than Alb-adsorbed surface and also more amount of 


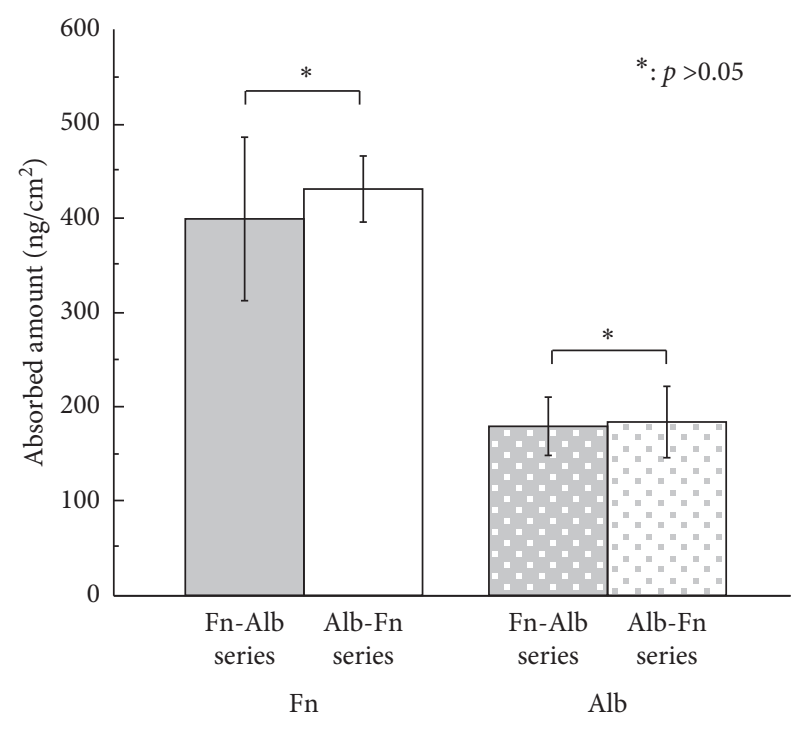

Figure 6: Adsorbed amounts of $\mathrm{Fn}$ and $\mathrm{Alb}$ on $\mathrm{ZrO}_{2}$ sensor in different two-step adsorption methods.

TABLE 2: $k_{\text {obs }}$ values for adsorption of Fn and Alb on $\mathrm{ZrO}_{2}$ sensor obtained 5 minutes after injection.

\begin{tabular}{lcc}
\hline Method & Fn $k_{\text {obs }}\left(\times 10^{-3}\right)$ & Alb $k_{\text {obs }}\left(\times 10^{-3}\right)$ \\
\hline Fn-Alb series & $10.05(0.59)^{\mathrm{a}}$ & $2.68(1.26)^{\mathrm{b}}$ \\
Alb-Fn series & $7.17(0.74)^{\mathrm{c}}$ & $4.71(1.04)^{\mathrm{d}}$ \\
\hline
\end{tabular}

Values in brackets are SD. Different superscript letters indicate a significant difference $(P<0.05)$.

Alb adsorbed to Fn-adsorbed surface than UV-irradiated native surface. However, there were no distinct differences in the amounts of protein adsorption between the first and second adsorptions.

Electrostatic interaction is also an important factor in protein adsorption. The isoelectric points (IP) of Fn and Alb are very similar at 5.0-6.0 and 4.7-4.9, respectively $[20,28,29]$. Fn and Alb were negatively charged under the present condition of $\mathrm{pH}=7.4$. Yoshida and Hayakawa [20] reported that the zeta potentials of $\mathrm{ZrO}_{2}$ after UV irradiation at $\mathrm{pH}=7.4$ were approximately $-43 \mathrm{mV}$ by the streaming potential method. These results indicated that the surface of $\mathrm{ZrO}_{2}$ is also negatively charged at the present conditions. Thus, electric repulsion occurred between each protein, Fn or Alb, and UV-irradiated native surface. It is suggested that the adsorption behavior of Fn to UV-irradiated native surface at the first step of adsorption was the results of the positive effect in adsorption due to the hydrophilic interaction and the negative results due to the electrostatic repulsion. Rezwan et al. investigated the adsorption of BSA to alumina, silica, titania, and $\mathrm{ZrO}_{2}$ particles [30]. They reported that adsorbed amounts of BSA to alumina, silica, and titania are highly correlated with the zeta potential, but not on the zirconia. They also suggested that hydrophobic effect plays a more important role than electro static interaction for zirconia adsorption. However, it is suggested that another factor besides surface roughness, hydrophilicity, and electrostatic interaction influence the two-step adsorption behaviors in the present study.

Pegueroles et al. recorded an increase in frequency of Alb adsorption on Fn preadsorbed surfaces [21]. They suggested that Alb molecules displaced some of the Fn molecules through displacement interactions due to the Vroman effect [31], in which proteins with stronger binding affinities competitively displace earlier adsorbed higher-concentration proteins. They speculated that Alb has a higher affinity for the $\mathrm{TiO}_{2}$ surface than Fn. Imagami et al. also suggested that the difference between affinities of Fn and Alb to Ti may influence the second protein adsorption behavior [22]. For the Ti surface, Alb showed a higher affinity than Fn. In the present study, more remaining molecules of Fn were observed on the $\mathrm{ZrO}_{2}$ surface after rinsing the Fn-adsorbed surface due to the higher affinity of Fn for the $\mathrm{ZrO}_{2}$ surface than Alb. Protein affinity to the $\mathrm{ZrO}_{2}$ surface was reversed to the Ti surface. It is presumed that this difference between protein affinities of $\mathrm{Ti}$ and $\mathrm{ZrO}_{2}$ may influence the protein adsorption behaviors. However, a clear mechanism has yet to be discovered. Other factors, such as conformational and electrical changes of preadsorbed proteins, contribute to the adsorption of protein at the second step. A more detailed surface analysis after the first-step adsorption is required.

The results of $k_{\mathrm{obs}}$ indicated that the protein-adsorbed surface delayed the second-step adsorption rate. This result is the same as that for the Ti surface as previously reported [22]. It was concluded that protein preadsorbed surfaces induce rapid adsorption of proteins at the second step. More surface characterizations after protein adsorption should be needed. It is suggested that surface roughness or hydrophilicity may influence the adsorption rate of proteins.

There are various types of proteins in living tissues, and their adsorption behaviors are more complex. In body fluids, albumin concentration is higher than fibronectin, and the difference in the concentration of proteins also influences the adsorption behavior. Moreover, competitive or step-wise protein adsorption to the implant material may occur. The analysis of competitive adsorption is more complex and difficult. So, we intended to analyze step-wise protein adsorption at first. As a series of step-wise protein adsorption experiment, we designed the simplest experiments model of step-wise adsorption. Same concentrations of proteins are used for two-step adsorption in this preliminary experiment. In the future, we will further investigate the two- or threestep adsorption behaviors of proteins of different concentrations to obtain the information about protein adsorption on implant materials in vivo. Other proteins such as osteocalcin and osteopontin play a key role in bone formation and osseointegration. The two- or three-step adsorption behaviors of proteins with different concentrations will be further investigated to obtain information about protein adsorption on implant materials.

\section{Conclusion}

We investigated the two-step adsorption of Fn and Alb on $\mathrm{ZrO}_{2}$ as an implant material using the QCM method. There were no significant differences in the adsorbed amounts of 
Fn and Alb between the different two-step adsorption series $(P>0.05)$. In contrast, the adsorption rate in the second step of adsorption was significantly slower than that in the first step of adsorption for both Fn and Alb adsorption $(P<0.05)$. There was no clear correlation between the amount of protein adsorbed by the $\mathrm{ZrO}_{2}$ sensor and surface topography.

It was concluded that the amount of protein adsorbed on the $\mathrm{ZrO}_{2}$ surface was not influenced by the two-step adsorption series, but the adsorption rate of proteins in the second step was affected by the first-step protein adsorption.

\section{Data Availability}

The data used to support the findings of this study are included within the article.

\section{Conflicts of Interest}

The authors declare that there are no conflicts of interest associated with this study.

\section{Acknowledgments}

This work was supported by the Grants-in-Aid for Scientific Research (C) from the Japan Society for the Promotion of Science (JP20K10021 and 21K09964).

\section{References}

[1] T. Albrektsson, G. Zarb, P. Worthington, and A. R. Eriksson, "The long-term efficacy of currently used dental implants: a review and proposed criteria of success," The International Journal of Oral \& Maxillofacial Implants, vol. 1, no. 1, pp. 11-25, 1986.

[2] R. Trindade, T. Albrektsson, P. Tengvall, and A. Wennerberg, "Foreign body reaction to biomaterials: on mechanisms for buildup and breakdown of osseointegration," Clinical Implant Dentistry and Related Research, vol. 18, no. 1, pp. 192-203, 2016.

[3] B. Kasemo and J. Lausmaa, "The biomaterial-tissue interface and its analogues in surface science and technology," The Bone-Biomaterial Interface, pp. 19-32, University of Toronto Press, Toronto, Canada, 1991.

[4] O. M. Omar, M. E. Lennerås, F. Suska et al., "The correlation between gene expression of proinflammatory markers and bone formation during osseointegration with titanium implants," Biomaterials, vol. 32, no. 2, pp. 374-386, 2011.

[5] R. C. Garvie, R. H. Hannink, and R. T. Pascoe, "Ceramic steel?” Nature, vol. 258, no. 5537, pp. 703-704, 1975.

[6] F. F. Lange, "Transformation toughening: part 3. Experimental observations in the $\mathrm{ZrO}_{2}-\mathrm{Y}_{2} \mathrm{O}_{3}$ system," Journal of Materials Science, vol. 17, no. 1, pp. 240-246, 1982.

[7] A. G. Evans, "Perspective on the development of hightoughness ceramics," Journal of the American Ceramic Society, vol. 73, no. 2, pp. 187-206, 1990.

[8] C. Piconi and G. Maccauro, "Zirconia as a ceramic biomaterial," Biomaterials, vol. 20, no. 1, pp. 1-25, 1999.

[9] E. Valentine-Thon and H. W. Schiwara, "Validity of MELISA for metal sensitivity testing," Neuro Endocrinology Letters, vol. 24, no. 1-2, pp. 57-64, 2003.
[10] F. H. Schünermann, M. E. Galárraga-Vinueza, R. Magini et al., "Zirconia surface modifications for implant dentistry," Materials Science and Engineering C, vol. 98, pp. 1294-1305, 2019.

[11] M. Hirota, T. Harai, S. Ishibashi, M. Mizutani, and T. Hayakawa, "Cortical bone response toward nanosecondpulsed laser-treated zirconia implant surfaces," Dental Materials Journal, vol. 38, no. 3, pp. 444-451, 2019.

[12] T. Hanawa, "Zirconia versus titanium in dentistry: a review," Dental Materials Journal, vol. 39, no. 1, pp. 24-36, 2020.

[13] M. Yoshinari, "Future prospects of zirconia for oral implants-a review," Dental Materials Journal, vol. 39, no. 1, pp. 37-45, 2020.

[14] M. C. L. Martins, S. R. Sousa, J. C. Antunes, and M. A. Barbosa, "Protein adsorption characterization," Methods in Molecular Biology, vol. 811, pp. 141-161, 2011.

[15] G. n. Sauerbrey, "Verwendung von schwingquarzen zur wägung dünner schichten und zur mikrowägung," Zeitschrift für Physik, vol. 155, no. 2, pp. 206-222, 1959.

[16] B. Becker and M. A. Cooper, "A survey of the 2006-2009 quartz crystal microbalance biosensor literature," Journal of Molecular Recognition, vol. 24, no. 5, pp. 754-787, 2011.

[17] R. E. Speight and M. A. Cooper, "A survey of the 2010 quartz crystal microbalance literature," Journal of Molecular Recognition, vol. 25, no. 9, pp. 451-473, 2012.

[18] C. J. Fee, "Label-free, real-time interaction and adsorption analysis 2: quartz crystal microbalance," Methods in Molecular Biology, vol. 996, pp. 313-322, 2013.

[19] Y. Kusakawa, E. Yoshida, and T. Hayakawa, "Protein adsorption to titanium and zirconia using a quartz crystal microbalance method," BioMed Research International, vol. 2017, Article ID 1521593, 8 pages, 2017.

[20] E. Yoshida and T. Hayakawa, "Adsorption analysis of lactoferrin to titanium, stainless steel, zirconia, and polymethyl methacrylate using the quartz crystal microbalance method," BioMed Research International, vol. 2016, Article ID 3961286, 7 pages, 2016.

[21] M. Pegueroles, C. Tonda-Turo, J. A. Planell, F. J. Gil, and C. Aparicio, "Adsorption of fibronectin, fibrinogen, and albumin on $\mathrm{TiO}_{2}$ : time-resolved kinetics, structural changes, and competition study," Biointerphases, vol. 7, no. 1-4, p. 48, 2012.

[22] H. Imagami, H. Nomoto, T. Nomura et al., "Analysis of twostep adsorption of proteins onto a titanium surface using a quartz crystal microbalance method," Journal of Japanese Society of Oral Implantology, vol. 33, no. 2, pp. 51-58, 2020.

[23] E. Yoshida and T. Hayakawa, "Quantitive analysis of apatite formation on titanium and zirconia in a simulated body fluid solution using the quartz crystal microbalance method," Advances in Materials Science and Engineering, vol. 2017, Article ID 7928379, 9 pages, 2017.

[24] W. Att, M. Takeuchi, T. Suzuki, K. Kubo, M. Anpo, and T. Ogawa, "Enhanced osteoblast function on ultraviolet lighttreated zirconia," Biomaterials, vol. 30, no. 7, pp. 1273-1280, 2009.

[25] M. Hirota and T. Hayakawa, "Adsorption behaviors of salivary pellicle proteins onto denture base metals using $27-\mathrm{MHz}$ quartz crystal microbalance," Bio-Medical Materials and Engineering, 2020, in Press.

[26] M. Hanning and A. Joiner, "The structure, function and properties of acquired pellicle," Monographs in Oral Science: The Teeth and Their Environment, vol. 19, pp. 29-64, 2006.

[27] J. Wei, T. Igarashi, N. Okumori et al., "Influence of surface wettability on competitive protein adsorption and initial 
attachment of osteoblasts," Biomedical materials (Bristol, England), vol. 4, no. 4, Article ID 045002, 2009.

[28] S. Ge, K. Kojio, A. Takahara, and T. Kajiyama, "Bovine serum albumin adsorption onto immobilized organotrichlorosilane surface: influence of the phase separation on protein adsorption patterns," Journal of Biomaterials Science, Polymer Edition, vol. 9, no. 2, pp. 131-150, 1998.

[29] K. Imamura, M. Shimomura, S. Nagai, M. Akamatsu, and K. Nakanishi, "Adsorption characteristics of various proteins to a titanium surface," Journal of Bioscience and Bioengineering, vol. 106, no. 3, pp. 273-278, 2008.

[30] K. Rezwan, A. R. Studart, J. Vörös, and L. J. Gauckler, "Change of $\zeta$ potential of biocompatible colloidal oxide particles upon adsorption of bovine serum albumin and lysozyme," The Journal of Physical Chemistry B, vol. 109, no. 30, pp. 1446914474, 2005.

[31] S. L. Hirsh, D. R. McKenzie, N. J. Nosworthy, J. A. Denman, O. U. Sezerman, and M. M. M. Bilek, "The Vroman effect: competitive protein exchange with dynamic multilayer protein aggregates," Colloids and Surfaces B: Biointerfaces, vol. 103, pp. 395-404, 2013. 